\title{
Making sense of climate engineering: a focus group study of lay publics in four countries
}

\author{
Victoria Wibeck $^{1}$ (D) • Anders Hansson ${ }^{1}$ • Jonas Anshelm ${ }^{2}$ • \\ Shinichiro Asayama ${ }^{3} \cdot$ Lisa Dilling ${ }^{4}$. \\ Pamela M. Feetham ${ }^{5}$ - Rachel Hauser ${ }^{6}$ - Atsushi Ishii ${ }^{7}$. \\ Masahiro Sugiyama ${ }^{8}$
}

Received: 3 March 2017 / Accepted: 28 August 2017 / Published online: 20 September 2017

(C) The Author(s) 2017. This article is an open access publication

\begin{abstract}
This study explores sense-making about climate engineering among lay focus group participants in Japan, New Zealand, the USA and Sweden. In total, 23 qualitative focus group interviews of 136 participants were conducted. The analyses considered sense-making strategies and heuristics among the focus group participants and identified commonalities and variations in the data, exploring participants' initial and spontaneous reactions to climate engineering and to several recurrent arguments that feature in scientific and public debate (e.g. climate emergency). We found that, despite this study's wide geographical scope, heterogeneous focus group compositions, and the use of different moderators, common themes emerged. Participants made sense of climate engineering in similar ways, for example, through context-dependent analogies and metaphorical
\end{abstract}

Electronic supplementary material The online version of this article (https://doi.org/10.1007/s10584-0172067-0) contains supplementary material, which is available to authorized users.

Victoria Wibeck

victoria.wibeck@liu.se

1 Centre for Climate Science and Policy Research, Department of Thematic Studies Environmental Change, Linköping University, Linköping, Sweden

2 Department of Thematic Studies, Technology and Social Change, Linköping University, Linköping, Sweden

3 Faculty of Political Science and Economics, Waseda University, Tokyo, Japan

4 Environmental Studies Program and Center for Science and Technology Policy Research, Cooperative Institute for Research in Environmental Sciences, University of Colorado, Boulder, USA

5 Communication Journalism and Marketing, Massey University, Palmerston North, New Zealand

6 Capacity Center for Climate \& Weather Extremes (C3WE), NCAR/UCAR, Boulder, USA

7 Center for Northeast Asian Studies, Tohoku University, Sendai, Japan

8 Policy Alternatives Research Institute, The University of Tokyo, Tokyo, Japan 
descriptions. With few exceptions, participants largely expressed negative views of large-scale deliberate intervention in climate systems as a means to address anthropogenic global warming.

Keywords Climate engineering - Geoengineering - Sense-making · Focus group · Cross-country Analysis $\cdot$ Analogies $\cdot$ Metaphors

\section{Introduction}

In December 2015, the international community reached a landmark agreement in Paris to limit global mean temperature increase to well below $2{ }^{\circ} \mathrm{C}$. According to the Intergovernmental Panel on Climate Change, achieving this ambitious goal will require global deployment of technologies for net negative emissions (IPCC 2013). This prompted renewed scientific and policy discussions about the role of climate engineering technologies for carbon dioxide removal (CDR) as well as solar radiation management (SRM) (Smith et al. 2016). ${ }^{1}$

In light of such discussions, many scholars argue that there is an urgent need to assess the proposed climate engineering options from social and natural scientific perspectives (Healey and Rayner 2015). Climate engineering is a controversial topic in the scientific debates (Stilgoe 2015). For many observers, the Paris Agreement's 1.5 degree ambition was considered provocative as it requires immediate radical emission cuts and measures that enable net negative emissions to offset the effects of greenhouse gases, i.e. climate engineering (Guillemont 2017). One stance in the climate engineering debate presents the proposals as undesirable, unreliable and even incompatible with democracy (e.g. Hulme 2014; Macnaghten and Szerszynski 2013) while an opposing stance argues that it should at least be considered, or tested in small scale field experiments (e.g. Keith 2013). Social scientists have issued repeated calls to open up the framings of climate engineering and to explore broader public views of the prospects of engineering the global climate (Bellamy et al. 2016; Corner and Pidgeon 2010; Sugiyama et al. 2016). However, climate engineering is still largely unfamiliar to lay publics around the world (Wright et al. 2014).

This paper starts from the assumption that the analysis of lay people's sense-making is pertinent to research into global environmental change. As 'social processes [are] embedded in specific social systems' (Hackman and St.Clair 2012: 15), it is crucial to understand how the causes of, impacts of and responses to global environmental change are interpreted not only by experts and decision makers, but also by lay publics who likely draw on local knowledge and culturally conditioned interpretative frames. More specifically, engaging lay publics in an 'upstream' stage of the research and development of high-stake technologies such as climate engineering helps spur discussion of 'desired futures' (Corner and Pidgeon 2010: 32), and can identify ethical and justice concerns (McLaren et al. 2016).

This paper aims to explore how lay focus group participants in different cultural contexts make sense of the largely unfamiliar idea of large-scale technical interventions in the global climate. The study offers an in-depth exploration of pathways used by the study's participants to create meaning regarding climate engineering in the absence of strong related opinions, predispositions and given framings. The paper makes a novel contribution to research on lay representations of climate

\footnotetext{
${ }^{1}$ An often-cited definition of climate engineering, or geoengineering, is: 'the deliberate large-scale manipulation of the planetary environment to counteract anthropogenic climate change' (Royal Society 2009: 1.) Climate engineering is an umbrella term describing proposed technologies for either removing carbon dioxide from the air or reflecting sunlight.
} 
engineering by exploring focus group participants' sense-making in four geographically and culturally diverse countries: Japan, New Zealand, the USA and Sweden. By understanding sensemaking of an unfamiliar technological issue, the paper also contributes to the broader literature of how individuals reach opinions about potentially controversial technologies.

To this end, the paper addresses the following specific research questions:

- What communicative resources did the focus group participants use in making sense of climate engineering?

- What themes did participants raise in the focus group discussions, and what were the commonalities and variations in how these themes were discussed?

- How were participants' lines of argument supported?

\section{Climate engineering and early public engagement}

Climate engineering is seen as an ideal case for 'upstream public engagement' (Sugiyama et al. 2016) as many of the proposed techniques are still hypothetical, or very early in the research stage, and social representations are unlikely to have formed. Corner and Pidgeon (2010) argue that public deliberation should be upstream, conducted by non-partisan organisations, include participants in forming agendas and be as representative and culturally diverse as possible.

Previous studies of public understanding of and engagement with climate engineering are mainly from the UK, North America (Bellamy et al. 2016; Corner et al. 2013; Kahan et al. 2015; Macnaghten and Szerszynski 2013; Pidgeon et al. 2012, 2013) and Germany (Amelung and Funke 2015; Braun et al. 2017; Merk et al. 2016), with a few exceptions from Sweden (Wibeck et al. 2015), Australia/New Zealand (Wright et al. 2014) and Switzerland (Sütterlin and Siegrist 2016). These studies map various and sometimes contradictory findings of public views on climate engineering. For instance, the Australian and New Zealand surveys (Wright et al. 2014) find generally negative views of climate engineering, particularly SRM techniques, while a few surveys in Canada, the UK and the USA report some support for SRM research (Carr et al. 2013). The UK focus group findings of Macnaghten and Szerszynski (2013), however, indicated that participants became more sceptical of climate engineering when faced with 'more realistic' descriptions of SRM. Merk et al. (2016) discount the 'moral hazard' argument that SRM might reduce incentives for taking action on mitigation; instead, people were more inclined to emphasise the importance of mitigation.

Previous qualitative research (e.g., Corner et al. 2013; Wibeck et al. 2015) illustrated how lay people draw on various cultural narratives and linguistic strategies to make sense of climate engineering. While these studies were conducted in the global North, this paper expands the geographical and cultural scope and the empirical basis of the previous research into lay sensemaking about climate engineering.

\section{Methods}

We refer to 'sense-making' as an interactive process by which people understand, describe and relate to their surroundings (Wibeck and Linnér forthcoming). From this perspective, sensemaking is not a purely cognitive process occurring in individual minds; rather, meaning is created in interaction with others, influenced by interactions between different ideas and 
arguments and shaped in relation to broader socio-cultural narratives and traditions (Marková et al. 2007).

Inspired by the interactionist view of sense-making, we employed a focus group method in the format of semi-structured interviews guided by a moderator and lasting 1-2 hours each (Wibeck et al. 2007). Focus groups are productive for analysing not only what participants think about various topics but also how they make sense of unfamiliar, controversial, or complex issues-i.e. 'joint meaning-making in action' (Wilkinson 2016). In particular, focus groups are useful for studying new topics emerging in public debate because they allow insights into how social representations are shaped (Marková et al. 2007).

In total, we conducted 23 focus groups involving 136 participants. Recruitment of focus group participants was topic blind, as climate engineering was not mentioned in the recruiting process. This prevented participants from reading up on climate engineering in advance, allowing spontaneous reactions rather than prepared responses. While each focus group was internally homogeneous in at least one key respect, our sample as a whole displays a wide range of cultural, geographical and socio-economic backgrounds (see Supplementary material, Table 1). The focus groups were held in regional university towns (in NZ, the USA and Sweden) and in a large metropolitan city (in Japan).

We first conducted the Swedish focus groups (Wibeck et al. 2015). Subsequent focus groups in Japan, New Zealand and the USA were slightly modified versions of the Swedish case, adjusted for their respective national contexts but preserving the main structure and including all the same questions. The focus group discussions started with open-ended questions that avoided predetermined frames. Information about climate engineering was gradually introduced during the sessions, allowing examination of participant reactions to common dominant frames in the scientific discourse, such as 'the climate emergency' and 'moral hazard' arguments (Merk et al. 2016; Nerlich and Jaspal 2012). All data were transcribed verbatim.

We conducted a horizontal analysis to explore recurrent themes and sense-making strategies across the data. First, we conducted a thematic analysis of each country's focus group discussions, segmenting and categorising the data according to the questions in the topic guide. To capture variations in the data, we also recorded topics that the participants raised spontaneously. From this initial analysis, we formulated themes that summarised larger parts of the focus group discussions.

Second, we scrutinised how participants made sense of climate engineering, by identifying and taking note of the various communicative strategies participants used to order, sort, and evaluate ideas related to climate engineering (cf. Wibeck and Linnér forthcoming). After this first inventory of sense-making strategies, we focused the analysis on one recurrent sensemaking strategy that was common across the focus groups, i.e. categorization: comparing the unfamiliar topic of climate engineering with other more familiar topics (cf. Marková et al. 2007). In categorising climate engineering, participants specifically used analogies between climate engineering and other, more familiar issues. While context-dependent and reflective of culturally specific conditions, many of these analogies could still be grouped into categories based on the types of arguments they expressed. A second strategy used by participants to categorise climate engineering was the use of metaphorical language. Similar to analogies, metaphors are powerful sense-making resources that highlight some aspects of a phenomenon while downplaying others (Nerlich and Jaspal 2012).

When interpreting this study's results, two caveats should be kept in mind. First, the fact that participants seemed to take anthropogenic climate change seriously, with very few expressing sceptical opinions about climate change, may have influenced their views of 
climate engineering. This is particularly notable in the case of the US focus groups, where, contrary to the country's divided public opinion, ${ }^{2}$ the participants all claimed to be concerned about climate change. Second, in Sweden, New Zealand and the USA — but not in Japan - the expression 'global environmental issues' was mentioned when recruiting participants. This may have helped attract participants with a particular interest in the environment to the first three countries' groups, while less so in the Japanese groups. However, the data as a whole captured variation in whether participants claimed to be interested in environmental issues. For example, in Sweden, several participants explicitly said they had no such interest, while several of the Japanese participants expressed their interest in the environment although this had not been mentioned in the focus group invitation.

\section{Results}

We sought both commonalities and variations in participants' sense-making across the focus groups. Surprisingly, we found clear commonalities concerning initial affective reactions to information about climate engineering, the participants' reasoning and explanations regarding their reactions, as well as the participants' final positions regarding climate engineering options.

\subsection{Unintended side effects and limits of human control of nature}

When the moderators first mentioned climate engineering, recurrent initial reactions were expressed by using the terms 'scary', 'risky' and 'science fiction'. With a few exceptionsparticularly in some of the Japanese groups - participants were largely critical of the prospect of climate engineering, sometimes reacting with disbelief or nervous laughter at the idea. One common theme in the focus group discussions related to the risk of unintended side effects as a consequence of climate engineering. Participants claimed that introducing climate engineering might lead to humankind's losing control of what it had started; despite good intentions to alleviate the impacts of climate change, deliberate large-scale manipulation of the global climate might have unforeseen negative consequences, making the situation even worse, especially for already vulnerable groups of people. In particular, participants expressed their fear that climate engineering might cause changes in ecosystem balance.

A common sense-making strategy in all countries was the use of analogies to advocate particular viewpoints on climate engineering. While the analogies were coloured by the national and cultural contexts in which they were expressed, they nevertheless expressed similar arguments. Participants would make analogies to the introduction of new species such as toads in Australia, Canada geese in Sweden or possums in New Zealand, arguing that what was done with good intentions, i.e. introducing new species into the fauna, ended in loss of control of the negative effects of these new species. Similarly, climate engineering was seen as possibly generating larger problems than the one it was meant to solve. An example illustrating this line of reasoning comes from the group of Japanese male middle-aged participants:

\section{Example 1:}

Perhaps it [climate engineering] will be technically doable, can be realized one day, but because some unintended effects will result, it will eventually end in vain. ... Because all

\footnotetext{
$\overline{{ }^{2} \mathrm{http} / / \text { climatecommunication.yale.edu/about/projects/global-warmings-six-americas/ }}$
} 
train lines are connected, one line to another, if a fatal accident happens in Gunma [north of Tokyo], a train running around Atami [south of Tokyo] will be stopped. So, you know, if Japan cools down, heat waves could hit the USA - such kinds of odd phenomena could happen. ... It's too big to control. You know, intuitively, I feel it's impossible. (Japan, Group D)

By making analogies with how the Tokyo train lines are interconnected and how accidents in one train line will affect other distant train lines, the participant in Example 1 suggests that climate engineering may result in less rather than more control over the climate, with unintended consequences occurring far beyond national borders.

Other examples of loss of control include analogies with building dams (USA), the use of DDT, or the dumping of industrial waste in the oceans (Sweden). In the effort to solve one problem, another bigger problem was created due to a lack of knowledge of negative side effects - or as one New Zealand participant put it, such technologies are like 'shooting in the dark' (Group A). In the words of one US participant, 'you think about everything from building dams to introducing invasive plants to control another plant, introducing predators. It always goes wrong' (Group B). Analogies were also repeatedly made with other large-scale, high-stake technologies, in particular nuclear power, where uncertainties and risks of unintended negative side effects were seen as major problems. Such analogies reinforce the view of climate engineering as risky and uncontrollable. Commonly, participants embraced the view that humanity should not intervene in complex systems that it cannot control or understand (cf. Corner et al. 2013).

It should be noted, however, that although most focus group participants reacted with fear and scepticism to the idea of climate engineering, quite a few participants in the Japanese groups deviated from the general critical stance towards climate engineering, and displayed enthusiasm for technological development in general (for details, see Asayama et al. 2017). To explain their optimism, these participants used analogies with recent technology innovations such as mobile phones or LED light bulbs to advocate for accelerated development of new technologies. Nonetheless, the focus groups making these supportive utterances also articulated most of the other themes presented through Sections 4.1-4.5.

\subsection{Treating the symptoms rather than the cause}

In the focus group discussions, participants often categorised climate engineering as merely treating symptoms, or as an extreme end-of-pipe solution that fails to address the core problem of anthropogenic climate change. The idea of attempting to remedy damage to the global climate system by developing large-scale technologies for global climate control was seen by many participants as a short-sighted solution, constituting a mere distraction from mitigation actions and lifestyle changes (see Section 4.3) and taking resources from the development of low-carbon energy technologies that should instead be prioritised.

Climate engineering was also seen as a way of 'shifting the problem' (NZ, Group $\mathrm{B}$ ), with the risk of causing 'environmental problems later that we are going to try and engineer around again' (US, Group A). An ethical dimension was raised in several groups, relating to unequal exposure not only to the impacts of climate change but also to the risks of climate engineering experimental research. This line of 
reasoning is illustrated by the following example from the New Zealand indigenous Māori group:

\section{Example 2:}

Which country is going to volunteer to be the experimental country? Usually it's the ones that probably can't afford it. Rather than doing that, why is there resistance to actually actioning some of the practical solutions that have been offered to them now ... and so rather than spending more money, because that really just adds to the cost globally - more money, more time, more delay - and while they are doing that our Pacific Islands have a high risk of being underwater before that is even completed when we have immediate solutions at hand. (New Zealand, Group E)

Example 2 summarises several of the thoughts frequently raised across the focus groups: the issue of climate (in)justice (cf. McLaren et al. 2016), outlining a scenario in which the poorest, already most vulnerable groups might become the subjects of climate engineering experimentation, and the risk that investing time and money in climate engineering research would displace investments in mitigation and adaptation (cf. Burns et al. 2016).

In discussing climate engineering as an end-of-pipe measure failing to address the core problem of climate change, a common strategy was to use analogies and metaphorical descriptions, particularly from medicine, such as 'you can't just plaster [i.e. bandage] the problem, you need to, like, get closer to the cause' (NZ, Group B), describing climate engineering as 'a blood pressure pill but no change of lifestyles' (NZ, Group B), or comparing climate engineering to cancer treatments that eventually make things worse (Japan, Group F; Sweden, Group C). Another analogy developed in the US senior citizen group (C) further illustrates this theme, with one participant saying that climate engineering was like 'taking the ambulance to the bottom of the cliff rather than eliminating the problem or working on the problem', reinforcing the 'moral hazard' argument that climate engineering constitutes a dangerous distraction rather than a solution to the climate crisis.

\subsection{Need for changes in lifestyles and consumption patterns}

The third recurrent theme was that lifestyle changes are necessary in rich countries due to overconsumption and a way of life that exhausts natural resources and destroys life-support conditions for humans and non-humans. Participants argued that the stresses on ecosystems could not continue, and that climate engineering was, in this context, just another way of maintaining business as usual. By making this categorization, participants concluded that climate engineering should be rejected in favour of systemic changes in energy production, transportation and consumer goods production. As one New Zealand Māori participant pointed out, 'the economic system does not work - [it] all needs to change drastically. A whole different thinking has to come out of it' (Group E). Similarly, one Swedish retiree asked: 'When will we reach that level where we understand that much less is enough?' (Group H). Another example comes from the Japanese group of middle-aged men, one of whom claimed that 'climate engineering sounds like we keep going along our current path by brute force, not cutting $\mathrm{CO}_{2}$ emissions, which are too high' (Group D).

Some participants expressed doubts as to whether people would voluntarily change their lifestyles, but when asked to choose between mitigation, adaptation and climate engineering, most participants strongly advocated mitigation on the individual and collective levels. 
Participants also claimed it was necessary to decrease consumption, to settle for less, both individually and collectively, and to orient oneself towards a less materialistic way of life. Several participants in the US mixed-age group argued that even though they were difficult, these changes were seen as imperative that people had come together to solve:

\section{Example 3:}

We learned how the American people and probably the world ... came together for the Second World War. Like we dropped everything and we joined the solution - what we thought that was at the time. And I think that by creating an environment of inclusiveness and team spirit, that is the way to actually motivate us to join the solution rather than being a part of the problem. (USA, group D)

By making an analogy to the sense of urgency during World War II, Example 3 illustrates the recurrent viewpoint that emergencies can lead to increased emphasis on structural and individual change and action. When comparing various responses to climate change, most participants from all four countries preferred mitigation to either adaptation or climate engineering. For example, one Japanese female senior made the argument for mitigation options through an analogy with car driving, arguing that 'it's the same with car driving - if you brake suddenly, you will fall down; if you try to stop it [climate change] artificially all of a sudden, it would be a bit of a stretch ... what is more important is to prevent car accidents from happening. It's better to take actions that make it [climate engineering] unneeded' (Group E).

This indicates that for the focus group participants, climate engineering seemed to have a 'reverse moral hazard' effect (Reynolds 2015), i.e. increased willingness to consider and even advocate behavioural changes, rather than being deterred by the introduction of new technologies for large-scale climate control. Leaving no room for doubts about what is at stake, climate engineering seemed to compel participants to take a stand regarding behavioural patterns in the rich countries that usually led to critical re-evaluation of their own lifestyles and the consumption culture permeating their parts of the world (cf. Corner and Pidgeon 2010; Merk et al. 2016; Sütterlin and Siegrist 2016).

\subsection{The need for political solutions}

A fourth recurrent theme centred on the concern that national and international policies may fail to achieve substantial reductions in greenhouse gas emissions. Individual politicians, national governments and international political organisations, such as the UN, were seen as unable to tackle climate change and agree on measures that really make a difference. Pessimism regarding the ongoing UN process dominated initial parts of the conversations across all focus groups. ${ }^{3}$ However, confronted with the idea of climate engineering, participants in most groups (although seldom in the Japanese groups) strongly emphasised that they preferred political solutions rather than large-scale technologies for controlling global climate. When climate engineering was introduced into the discussions as an alternative measure, participants re-evaluated the political measures and claimed that national governments and international political organisations have the responsibility to take action against climate change. Participants found the outlook of a climate-engineered planet so frightening that it prompted participants to claim that solutions, after all, must be political, and that

\footnotetext{
${ }^{3}$ Note that the focus groups were conducted before COP 21 and the Paris agreement.
} 
political failure was unacceptable. The following quote from one Swedish group of middle-aged citizens illustrates this reasoning:

\section{Example 4:}

One must not accept the statement that political solutions are not a way forward, but they are a path that you are not allowed to give up on. Maybe you have to surrender and fall back on something ... But I can't see how that would imply that you should stop the attempts already ongoing today. (Sweden, Group C)

The participant quoted in Example 4 emphasises that political solutions should be prioritised. The metaphor of 'path' used to advocate political agreements suggests that humanity can still choose to follow a particular strategy and that when one stops trusting in politics, one is already in a state of 'surrender'. Meanwhile, the metaphor of 'surrender' was used to make sense of what climate engineering implies. This 'surrender' metaphor contributed to categorising climate engineering as the opposite of a preferred option (i.e. mitigation) to tackle climate change, i.e. as a measure one reluctantly may have to fall back on, if all other possibilities are exhausted.

Even the participants who were open to climate engineering as a last resort (see Section 4.5), reiterated the need for international political regulation and the possibility of reaching international political agreement as a prerequisite for climate engineering governance. If climate engineering should be necessary in a future emergency, they claimed that it should be governed by international political organisations and not handed over to private corporations or superpowers such as China or the USA.

In the Japanese focus groups, the discussions differed somewhat, in that the idea of climate engineering did not lead to re-evaluation of the role of politics. While some Japanese participants explicitly said that mitigation should be prioritised, this did not necessarily lead to re-evaluation of the role of politics; rather, the participants identified the radical change of individual wasteful lifestyles as a primary course of action (see Section 4.3).

Notwithstanding, most participants saw climate engineering as yet another scary concept underlining the seriousness of the situation that world politics must address, and climate engineering was in this context interpreted as the final wake-up call.

\subsection{Keeping the door ajar for all options}

When the focus group moderators first introduced climate engineering, spontaneous reactions of fear and anxiety were widespread in most groups (see Section 4.1). However, these initial reactions were sometimes gradually renegotiated and at times ended in 'conditional support' for climate engineering research or the stance that, one should keep the door ajar for all options, including climate engineering. One example illustrating this stance comes from the Japanese group of middle-aged men, in which one participant claimed that it was not an 'either/or' argument, as to whether we should consider climate engineering an option, but a 'both/and' argument that we should pursue all available options. The participant summarised the options as follows: 'only mitigation' is the ideal way, adaptation is a pragmatic approach and climate engineering could be a last-resort option.

The focus groups recurrently debated whether the risks of catastrophic climate change constitute a case for climate engineering. The moderators' introduction of the climate emergency argument marked a turning point in some of the groups, leading participants to advocate research into climate engineering, despite their initial criticism. Participants in the Young 
Professionals group from New Zealand highlight this theme by using the 'tipping point' and 'safety net' metaphors:

\section{Example 5:}

W18: If you can prove you're past the tipping point, then I guess then there's nothing else you can do, apart from something like this.

W19: I believe that there is value in doing further research. It's quite good to know that research has been done and there could be something potentially made of this, so when a disaster, like crazy, happens in 2025 we have something to fall back on. Sort of a little bit of a safety net. (New Zealand, Group A)

Example 5 illustrates a line of reasoning in which support for climate engineering research was rationalised as humanity's last resort and - after set against the risks of climate change - as 'the lesser of two evils' (cf. Gardiner 2010).

Various reactions across the focus groups related to 'the climate emergency' argument. The most common response was for participants to emphasise the need for more serious efforts at mitigation and lifestyle changes (see Section 4.3, 4.4). In several cases, however, especially in the Japanese groups, the severity of the climate crisis seemed to legitimise support for research on climate engineering. A recurring stance in this regard was that humanity must explore all available options including climate engineering, despite its ethical, scientific and political downsides. Or, to quote an analogy employed by one US participant, 'it [climate engineering] is something that really needs to be looked at seriously, but it's kind of like nuclear weapons you know, it's like spend a lot of research in brain power and money trying to develop something that you never want to use' (Group D).

Participants seldom presented arguments for deployment of climate engineering, however. It is also noteworthy that support for research was usually heavily conditioned; for example, technology development must not be handed to big corporations, countries or other organisations considered able to weaponise climate engineering (cf. Macnaghten and Szerszynski 2013).

\section{Discussion}

Evaluating climate engineering requires lay persons to consider the associated risks and unknowns of new and hypothetical concepts. In the past, members of the public were thought to have a 'deficit' of knowledge that hindered their understanding of science and technology (Corner et al. 2011). However, recent research concludes that even with limited familiarity, lay persons are often able to reason and participate in debate about risks in science and technology. Lay persons may come into a research situation with limited knowledge of the research subject yet many participate in discussions wholeheartedly by drawing on shared cultural narratives (Corner et al. 2013; Macnaghten et al. 2015).

Building on earlier literature arguing for the importance of upstream public engagement with emerging high-stake technologies (e.g. Corner and Pidgeon 2010: 32), this paper contributes further insights into similarities and variations in how lay sense-making occurred (cf. Burns et al. 2016; Davies 2011) by analysing how analogies and metaphors served as tools for the focus group participants in grappling with ontological, epistemological and ethical aspects of climate engineering. As such, analogies and metaphors were key communicative resources in the focus groups, serving at least three types of rhetorical purposes. 
First, in struggling with coming to grips with and describing what climate engineering might entail, participants tried out comparisons with other technologies or phenomena that proved meaningful in their particular contexts, for example when Swedish participants compared the large-scale climate engineering proposals with large-scale nuclear power, which has long been a controversial issue in public debate in Sweden, or when Japanese participants related to transport infrastructure.

Second, similar to what has been found in analyses of public engagement with other new and emerging technologies such as GMO (Horlick-Jones et al. 2007), nanotechnology (Schwarz-Plaschg 2016) or information- and communication technology (Wyatt 2004), analogies and metaphors were not only used for description but more so for argumentation. Participants used them to anticipate and pass judgements on potential future developments (cf. Schwarz-Plaschg 2016; Wyatt 2004) as well as to evaluate the acceptability of climate engineering; an assessment which often ended in rejection due to anticipated negative side effects and ethical problems.

Third, as the focus group discussions, with few exceptions, ended in negative views of the prospects of climate engineering, an inevitable question triggered by climate engineering seemed to be: what sort of planet and/or world do we want to live in? (cf. Macnaghten and Szerszynski 2013). Here, analogies and metaphors played important roles in the participants' conceptualization of human-nature relationships (cf. Corner et al. 2013). In a previous study, Nerlich and Jaspal (2012) showed that the UK media discourses of climate engineering were based on three metaphorical concepts of the planet ('body', 'patient/addict', and 'machine'). Similarly, the five dominant climate engineering themes identified in our analysis can be seen as rooted in different conceptions of the planet: (1) 'the planet as a complex social-ecological system', (2) 'the planet as a patient addicted to fossil fuels' and (3) 'the planet as a political object of global sustainability'.

The first theme ('side effects and losing control') seems to be rooted in the conception of 'the planet as a complex social-ecological system' in which the socio-economic and biophysical spheres are intrinsically inseparable and interconnected. The analogies with foreign invasive species into indigenous ecosystems or with technology-based alterations of nature (e.g. dams, DDT, and GMOs) were used to highlight the complexity of human-environment interactions in the Earth system and the unpredictability and uncontrollability of technological intervention in nature, which led to the scepticism about climate engineering. The second ('symptom treatment') and third ('lifestyle change') themes centred on criticism of climate engineering as an end-of-pipe technology and a distraction from substantive mitigation efforts, which can be seen as based in a conception of 'the planet as a patient addicted to fossil fuels'. Through medical analogies, participants diagnosed consumerist cultures and lifestyles as fundamental causes of the climate change problem and blamed climate engineering as treating only the symptoms. While the 'medical fix' metaphors in scientific discourse tend to justify climate engineering as a cure for the planet's ills (Nerlich and Jaspal 2012), our focus group participants employed medical analogies to question it as a misguided treatment that keeps the patient (human society) addicted to fossil fuels rather than curing the disease. Last, the fourth ('need for political solutions') and fifth ('keeping the door ajar') themes shared the same vision that politics-as-usual is not an option, which seemingly rests on a conception of 'the planet as a political object of global sustainability'. The fourth theme envisions the radical transformation of today's political systems as the pathway to achieve global sustainability by perceiving climate engineering as a wake-up call for world politics. On the other hand, the fifth theme suggests that in a state of emergency exceeding dangerous climate thresholds, all available 
options, including climate engineering as a last resort, must be sought to strive for global sustainability.

The frequent use of categorizations through analogies and metaphors in the focus groups suggests that sense-making of climate engineering largely occurred through drawing out similarities between climate engineering and other issues which were more familiar to the participants. Notwithstanding, one could argue that at an overarching level, the focus group discussions also particularised climate engineering proposals as distinct from other emerging technologies (cf. Billig 1996). Similar particularization can be observed in the scientific literature. Unlike climate engineering, many other emerging technologies with potentially transformative impacts on society, such as genetically modified organisms, nanotechnology and nuclear power, have significant proportions of promoters and enthusiasts and are rhetorically tightly coupled with progressive and even utopian ideals that climate engineering lacks (Anshelm and Hansson 2014a, 2014b). By contrast, a review of peer-reviewed papers on climate engineering published between 2006 and 2013 found that few scientific publications ended in an explicit 'yes' or 'no' to climate engineering, and that less than $2 \%$ or the reviewed papers unconditionally advocated deployment (Linnér and Wibeck 2015). A common recommendation in the research literature is that more research and experimentation is needed, though such recommendations are accompanied by calls for caution (Dilling and Hauser 2013). Very few hopes of positive side effects, such as increased food production or economic growth, are connected to climate engineering (e.g. Linnér and Wibeck 2015). Expectations for climate engineering can even be described as negative or dystopian: scientists do not promise to succeed in developing climate engineering, and eventual deployment may not even benefit society aside from a chance of negating another major harm (i.e. climate change) (Anshelm and Hansson 2014a, 2014b).

Our focus group participants raised concerns that were significantly similar to those raised in scientific discourse, despite their generally low prior awareness of climate engineering. The participants could hardly identify any positive co-benefits of climate engineering beyond mere climate risk avoidance. On the contrary, participants identified grand-scale environmental risks and fundamental scientific and technological limitations in controlling these proposed technologies and their unintended consequences. Those participants who still advocated research into climate engineering primarily categorised it as a 'last resort', a means to avoid catastrophic impacts of climate change, thus any support for climate engineering was weak and heavily conditioned.

In future studies, it would be valuable to undertake a more in-depth exploration of the factors that led lay people to engage in sense-making strategies including those identified above, and to pay further attention to the interplay between categorization and particularization strategies for sensemaking. Such studies may include focus groups on other technologies for comparison purposes. Another option would be to focus the discussions on particular climate engineering proposals rather than on the overarching idea of large-scale technological climate interventions. For example, in the wake of the Paris agreement in December 2015, net negative emissions via CDR, particularly bioenergy with carbon capture and storage (BECCS), has reached the international climate agendas. The BECCS method already constitutes an important key for mitigation in several national longterm strategies, even though its practicality is not proven and several crucial societal aspects have not been deliberated over in wider contexts, if at all (Creutzig et al. 2014). The present study showed that although the focus group interviews had their main focus on how participants made sense of the overarching idea of climate engineering, the participants often chose to focus the discussions on the riskier and less controllable SRM options, arguably contributing to the more sceptical stances (cf. 
Sütterlin and Siegrist 2016). Communicating SRM and BECCS bundled together may, as shown in the present study, steer focus towards the more spectacular high-risk SRM options, and may also relativize the risks of BECCS, which also seem significant if assessed in isolation from SRM (e.g. loss of biodiversity, land-use conflicts, storage safety and water shortage; Buck 2016). In line with Buck (2016), we see a need for further exploration of sense-making about BECCS since many significant societal problems related to scaling up that method are not investigated and poorly understood.

Acknowledgements This work was supported by the Swedish Research Council [grant number 2012-1101], the Swedish Research Council Formas [grant number 2012-725] and the Environment Research and Technology Development Fund (1-1406) of the Ministry of the Environment, Japan.

Open Access This article is distributed under the terms of the Creative Commons Attribution 4.0 International License (http://creativecommons.org/licenses/by/4.0/), which permits unrestricted use, distribution, and reproduction in any medium, provided you give appropriate credit to the original author(s) and the source, provide a link to the Creative Commons license, and indicate if changes were made.

\section{References}

Amelung D, Funke J (2015) Laypeople's risky decisions in the climate change context: climate engineering as a risk-defusing strategy? Hum Ecol Risk Assess 21:533-559

Anshelm A, Hansson A (2014a) Battling Promethean dreams and Trojan horses: revealing the critical discourses of geoengineering. Energy Research \& Social Science 2:135-144

Anshelm J, Hansson A (2014b) The last chance to save the planet? An analysis of the geoengineering advocacy discourse in the public debate. Environmental Humanities 5:101-123

Asayama S, Sugiyama M, Ishii A (2017) Ambivalent climate of opinions: tensions and dilemmas in understanding geoengineering experimentation. Geoforum 80:82-92

Bellamy R, Chilvers J, Vaughan NE (2016) Deliberative mapping of options for tackling climate change: citizens and specialists 'open up' appraisal of geoengineering. Public Underst Sci 25:269-286

Billig M (1996) Arguing and thinking: a rhetorical approach to social psychology, 2nd edn. Cambridge University Press, Cambridge

Braun C, Merk C, Pönitzsch G, Rehdanz K, Schmidt U (2017) Public perception of climate engineering and carbon capture and storage in Germany: survey evidence. Clim Pol. https://doi.org/10.1080 /14693062.2017.1304888

Buck HJ (2016) Rapid scale-up of negative emissions technologies: social barriers and social implications. Clim Chang 139:155-167

Burns E et al (2016) What do people think when they think about solar geoengineering? A review of empirical social science literature, and prospects for future research. Earth's Future 4:536-542

Carr WA, Preston CJ, Yung L, Szerszynski B, Keith DW, Mercer AM (2013) Public engagement on solar radiation management and why it needs to happen now. Clim Chang 121:567-577

Corner A, Pidgeon N (2010) Geoengineering the climate: the social and ethical implications. Environment 52:24-37

Corner A, Parkhill K, Pidgeon N (2011) Experiment Earth? Reflections on a public dialogue on geoengineering. In: Understanding Risk Working Paper 11-02. School of Psychology, Cardiff

Corner A et al (2013) Messing with nature? Exploring public perceptions of geoengineering in the UK. Glob Environ Chang 23:938-947

Creutzig F et al (2014) Bioenergy and climate change mitigation: an assessment. GCB Bioenergy 7:909-1184

Davies S (2011) How we talk when we talk about nano: the future in laypeople's talk. Futures 43:317-326

Dilling L, Hauser R (2013) Governing geoengineering research: why, when and how? Clim Chang 121:553-565

Gardiner S (2010) Is arming the future with geoengineering really the lesser evil? In: Gardiner S et al (eds) Climate ethics: essential readings. Oxford University Press, Oxford

Guillemont, H., 2017. The necessary and inaccessible 1.5C objective: a turning point in the relations between climate science and politics? In Aykut, S.C., et al., (Eds.). Globalising the climate. Routledge, Abingdon

Hackman H, St.Clair AL (2012) Transformative cornerstones of social science research for global change. ISSC, Paris

Healey P, Rayner S (2015) Key findings from the climate geoengineering governance project. In: CGG working paper 25. University of Oxford, Oxford 
Horlick-Jones T, Walls J, Kitzinger J (2007) Bricolage in action: learning about, making sense of, and discussing issues about genetically modified crops and food. Health, Risk \& Society 9:83-103

Hulme, M., 2014. Can science fix climate change? A case against climate engineering. Polity Press, UK, Cambridge

IPCC (2013) Climate change 2013: the physical science basis. Cambridge University Press, Cambridge

Kahan DM et al (2015) Geoengineering and climate change polarization. Annals of American Academy of Political \& Social Science 658:192-222

Keith D (2013) A case for climate engineering. MIT Press, Cambridge, MA

Linnér B-O, Wibeck V (2015) Dual high-stake emerging technologies: a review of the climate engineering research literature. WIREs Climate Change 6:255-268

Macnaghten P, Szerszynski B (2013) Living the global social experiment: an analysis of public discourse on solar radiation management and its implications for governance. Glob Environ Chang 23:465-474

Macnaghten, P., Davies, S.R., Kearnes, M., 2015. Understanding public responses to emerging technologies: A narrative approach. Journal of Environmental Policy \& Planning, doi: 1080/1523908X.2015.1053110

Marková, I., et al., 2007. Dialogue in focus groups. Equinox, London

McLaren D et al (2016) Public conceptions of justice in climate engineering. Glob Environ Chang 41:64-73

Merk C, Pönitzsch G, Rehdanz K (2016) Knowledge about aerosol injection does not reduce individual mitigation efforts. Environ Res Lett 11(5)

Nerlich B, Jaspal R (2012) Metaphors we die by? Geoengineering, metaphors, and the argument from catastrophe. Metaphor Symb 27:131-147

Pidgeon N et al (2012) Exploring early public responses to geoengineering. Phil Trans R Soc A 370:4176-4196

Pidgeon N et al (2013) Deliberating stratospheric aerosols for climate geoengineering and the SPICE project. Nat Clim Chang 3:451-457

Reynolds J (2015) A critical examination of the climate engineering moral hazard and risk compensation concern. The Anthropocene Review 2:174-191

Royal Society, 2009. Geoengineering the climate. The Royal Society, London, UK

Schwarz-Plaschg C (2016) Nanotechnology is like ... the rhetorical roles of analogies in public engagement. Public Underst Sci. https://doi.org/10.1177/0963662516655686

Smith P et al (2016) Biophysical and economic limits to negative $\mathrm{CO}_{2}$ emissions. Nat Clim Chang 6:42-50

Stilgoe J (2015) Experiment earth: responsible innovation in geoengineering. Routledge, Abingdon

Sugiyama M et al (2016) Transdisciplinary co-design of scientific research agendas: 40 research questions for socially relevant climate engineering research. Sustain Sci. https://doi.org/10.1007/s11625-016-0376-2

Sütterlin B, Siegrist M (2016) Public perception of solar radiation management. Journal of Risk Research. https://doi.org/10.1080/13669877.2016.1153501

Wibeck, V., Linnér, B.-O., forthcoming. Sense-making analysis: a framework for multi-strategy and crosscountry research. Submitted manuscript.

Wibeck V, Öberg G, Abrandt-Dahlgren M (2007) Learning in focus groups: an analytical dimension for enhancing focus group research. Qual Res 7:249-262

Wibeck V, Hansson A, Anshelm J (2015) Questioning the technological fix to climate change: lay sense-making of geoengineering in Sweden. Energy Research \& Social Science 7:23-30

Wilkinson S (2016) Analysing focus group data. In: Silverman D (ed) Qualitative research, 4th edn. Sage Publications, London

Wright MJ, Teagle DAH, Feetham P (2014) A quantitative evaluation of the public response to climate engineering. Nat Clim Chang 4:106-110

Wyatt S (2004) Danger! Metaphors at work in economics, geophysiology, and the internet. Sci Technol Hum Values 29:242-261 